\title{
Numerical Study of Radical Reaction in Kerosene Auto-ignition
}

\author{
LI Lana, CHEN Qi-sheng ${ }^{b}$ \\ aState Key Laboratory of Laser Propulsion \& Application, Equipment Academy, Beijing 101416, \\ China \\ ${ }^{\mathrm{b}}$ China Aerodynamics Research and Development Center, Mianyang Sichuan 621000,China \\ allnudt@163.com, bchensheng_atp@126.com
}

Keywords: Surrogate fuel, combustion mechanism, $\mathrm{OH}$ radical, reaction path

\begin{abstract}
Spontaneous emission signal had different curves of kerosene's auto-ignition in shock tube under different temperature conditions, and $\mathrm{OH}^{*}$ radicals concentration time history was numerically investigated. Two component surrogate fuel model (n-decane+trimethylbenzene) was used to validate consistency of its ignition delay time data with kerosene. Then simulation of $\mathrm{OH}^{*}$ time history during reaction was carried out using the surrogate fuel model's combustion mechanism. $\mathrm{OH}^{*}$ radicals' sensitivity analysis and reaction paths of production and consumption were investigated under different temperatures. The results show that the difference of dominant reactions for radicals' consumption lead to different curves of $\mathrm{OH}^{*}$ radicals traces, which was that two peaks curve would present more easily under lower temperature and one peak curve under higher temperature.
\end{abstract}

\section{Introduction}

Aviation kerosene is a complex fuel containing naphthenic hydrocarbon, alkane and aromatic hydrocarbon. Its fundamental combustion characteristics are important for engine's design modification, combustion efficiency improvement, and el al. Many research group has conducted ignition delay time measurements on the shock tube system. Our lab has set up an aerosol shock tube system, and carried out ignition delay time study of several different hydrocarbon fuels. Ignition time after the reflected shock wave was the key parameter of judgement, and there are two ways. One way is the rise step of pressure curve after combustion, and the other is radicals' emission during combustion ${ }^{[1]}$. Optical emission is more prior to adopt. Emission signal of $\mathrm{CH}^{*}$ or $\mathrm{OH}^{*}$ collected by PMT (431nm or 306nm nearby) was used as the initiation time of ignition ${ }^{[2]}$. According to the premixed fuel with mass diluent gas, ignition delay time differences between side wall or end face measurement can be ignored ${ }^{[3]}$. We have studied the ignition delay time of RP-3 under different temperatures and equivalence ratios, and accumulated plenty of time data. We observed the two peaks curve in $\mathrm{OH}^{*}$ emission signal ,which is more obvious in low temperature. This phenomena was coincident with the absorption spectrum measurement results ${ }^{[4]}$.

In order to analysis $\mathrm{OH}^{*}$ production process from kinetic field, the reaction process should be studied according to combustion mechanism. For kerosene's complex constituents, suitable surrogate fuel model was always adopted. The surrogate fuel model has been widely studies both in China and aboard, which included single component, three components and six components model $^{[5-7]}$.Honnet, et al ${ }^{[9]}$ from Aachen University developed a two components model (80\% n-decane+20\%trimethylbenzene) and validated the mechanism through shock tube, rapid compression machine, and premix combustion experiments.

The simulation results with Honnet's mechanism was close to our RP-3 kerosene (equivalence formular: $\mathrm{C}_{10} \mathrm{H}_{22}$ ) ignition delay time data, as shown in Fig.1. So this article investigated $\mathrm{OH}^{*}$ radicals production process and reaction paths based on Honnet's mechanism using CHEMKIN-PRO. 


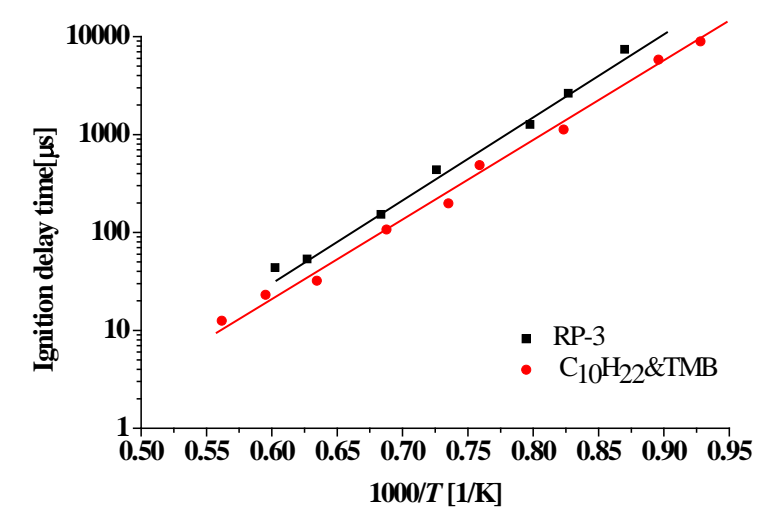

Fig.1 Comparison of ignition delay times of kerosene and surrogate fuel ${ }^{[10]}$

\section{Combustion mechanism and validation}

The mechanism contains 119 species and 527 reactions, whose main cracking reactions can be searched from Ref[9]. Ignition process was simulated under $\mathrm{T}=1500 \mathrm{~K}, \mathrm{P}=1 \mathrm{~atm}$, and equivalence ratio=1.0, the temperature and $\mathrm{O}_{2}$ mole fraction were show in Fig.2.

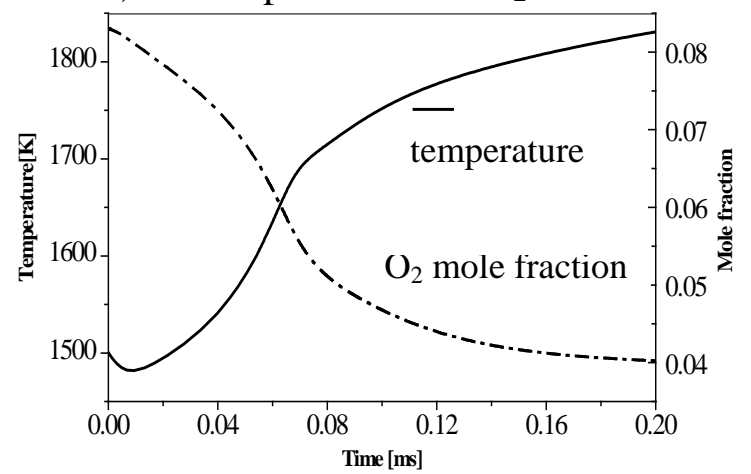

Fig.2 Temperature and $\mathrm{O}_{2}$ mole fraction curve( $\mathrm{T}=1500 \mathrm{~K}, \mathrm{P}=1 \mathrm{~atm}, \phi=1.0)$

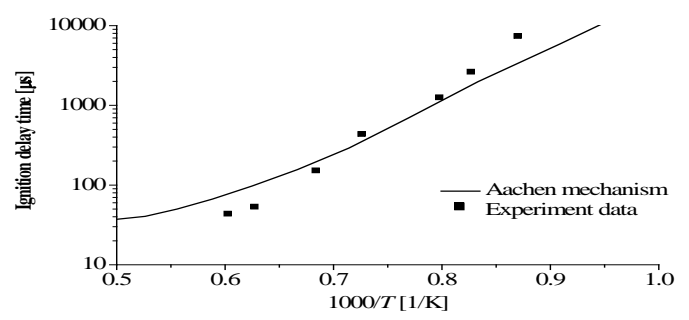

Fig.3 Comparison of ignition delay time data of experiments and simulation $(\mathrm{P}=1 \mathrm{~atm}, \phi=1.0)$

It can be concluded that $\mathrm{O}_{2}$ mole fraction begin to decrease from beginning, and temperature decrease at the first $0.01 \mathrm{~ms}$ and then increase, which due to radicals accumulation at the initiation stage and endothermic reaction. The ignition delay time data and simulation results were compared under broader temperature range and shown in Fig.3. The data coincide with each other mainly in intermediate temperature range (about 1200 1500K).

\section{OH radicals sensitivity analysis and reaction path analysis}

$\mathrm{OH}^{*}$ radicals, remarking ignition delay time, was used to conduct sensitivity analysis (Fig.4). Elementary reactions, R1,R3,R30,R46,R50,R67,R69,R107,R112,R138, were all in favour of ignition delay time decreasing, in which R1 had highest sensitivity. While R8,R34,R72 were all in favour of increasing, and R34 had highest sensitivity. 
Table 1. Main reactions influencing ignition delay time $(\mathrm{T}=1700 \mathrm{~K}, \mathrm{P}=1 \mathrm{~atm}, \quad \phi=1.0)$

\begin{tabular}{|c|c|c|c|c|c|}
\hline $\begin{array}{l}\text { Elementary } \\
\text { reaction } \\
\text { number } \\
\end{array}$ & Reaction formula & $\begin{array}{l}\text { Effect on } \\
\text { ignition } \\
\text { delay time } \\
\end{array}$ & $\begin{array}{l}\text { Elementary } \\
\text { reaction } \\
\text { number }\end{array}$ & Reaction formula & $\begin{array}{l}\text { Effect on } \\
\text { ignition } \\
\text { delay time }\end{array}$ \\
\hline $\mathrm{R} 1$ & $\mathrm{H}+\mathrm{O}_{2}<=>\mathrm{OH}+\mathrm{O}$ & (reduce) & R67 & $\mathrm{OH}+\mathrm{CH}_{3}<=>\mathrm{PXCH}_{2}+\mathrm{H}_{2} \mathrm{O}$ & (reduce) \\
\hline R3 & $\mathrm{OH}+\mathrm{H}_{2}<=>\mathrm{H}_{2} \mathrm{O}+\mathrm{H}$ & (reduce) & R69 & $\mathrm{CH}_{3}+\mathrm{HO}_{2}<=>\mathrm{CH}_{3} \mathrm{O}+\mathrm{OH}$ & (reduce) \\
\hline R8 & $\mathrm{HO}_{2}+\mathrm{OH}<=>\mathrm{H}_{2} \mathrm{O}+\mathrm{O}_{2}$ & (increase) & R72 & $\mathrm{CH}_{3}+\mathrm{H}(+\mathrm{M})<=>\mathrm{CH}_{4}(+\mathrm{M})$ & (increase) \\
\hline R30 & $\mathrm{HCO}+\mathrm{M}<=>\mathrm{CO}+\mathrm{H}+\mathrm{M}$ & (reduce) & R107 & $\mathrm{C}_{2} \mathrm{H}_{2}+\mathrm{O}<=>\mathrm{HCCO}+\mathrm{H}$ & (reduce) \\
\hline R34 & $\mathrm{HCO}+\mathrm{OH}<=>\mathrm{CO}+\mathrm{H}_{2} \mathrm{O}$ & (increase) & R112 & $\mathrm{C}_{2} \mathrm{H}_{3}(+\mathrm{M})<=>\mathrm{C}_{2} \mathrm{H}_{2}+\mathrm{H}(+\mathrm{M})$ & (reduce) \\
\hline R46 & \multirow{2}{*}{$\begin{aligned} & \mathrm{TXCH}_{2}+\mathrm{O}_{2} \\
= & >\mathrm{CO}+\mathrm{OH}+\mathrm{H} \\
& \mathrm{PXCH}{ }_{2}+\mathrm{O}_{2} \\
= & >\mathrm{CO}+\mathrm{OH}+\mathrm{H}\end{aligned}$} & (reduce) & R138 & $\mathrm{C}_{2} \mathrm{H}_{4}+\mathrm{OH}<=>\mathrm{C}_{2} \mathrm{H}_{3}+\mathrm{H} 2 \mathrm{O}$ & (reduce) \\
\hline \multirow[t]{14}{*}{$\mathrm{R} 50$} & & (reduce) & & & \\
\hline & \multicolumn{2}{|c|}{$1700 \mathrm{~K}$} & R138 & & \\
\hline & & & R112 & & \\
\hline & & & R107 & & \\
\hline & & & & R72 & \\
\hline & & & R69 & & \\
\hline & & & R67 & & \\
\hline & & & $\mathrm{R} 50$ & & \\
\hline & & & R46 & & \\
\hline & & & & R34 & \\
\hline & & & R30 & & \\
\hline & & & & R8 & \\
\hline & & & R3 & & \\
\hline & & -0.3 & $\left.-\tau_{0}\right) / \tau_{0}^{-0.1}$ & 0.1 & \\
\hline
\end{tabular}

Fig.4 Sensitivity analysis of ignition delay time ( $\mathrm{T}=1700 \mathrm{~K}, \mathrm{P}=1 \mathrm{~atm}, \phi=1.0)$

Fig. 5 compared $\mathrm{OH}^{*}$ reaction paths under different temperatures. $\mathrm{OH}^{*}$ production was due to R1, but reaction rate were different under ignition temperature of $1400 \mathrm{~K}$ and $1700 \mathrm{~K}$. $\mathrm{OH}^{*}$ production from reaction R1 increased gradually in lower temperature and reached peak in $0.22 \mathrm{~ms}$. While in higher temperature, $\mathrm{OH}^{*}$ reached peak in a short time for $\mathrm{R} 1$, fell back in a small range and reached peak again in $0.03 \mathrm{~ms}$. For $\mathrm{OH}^{*}$ 's consumption, reactions R3 and R20 dominated and reached consumption peak slightly before R1's production peak under lower temperature. For mass consumption before production peak, $\mathrm{OH}^{*}$ emission curve exhibited double peaks. When temperature was higher, $\mathrm{OH}^{*}$ radicals were consumed from beginning until the production peak, so the global consumption lead to one peak structure of $\mathrm{OH}^{*}$ emission curve.

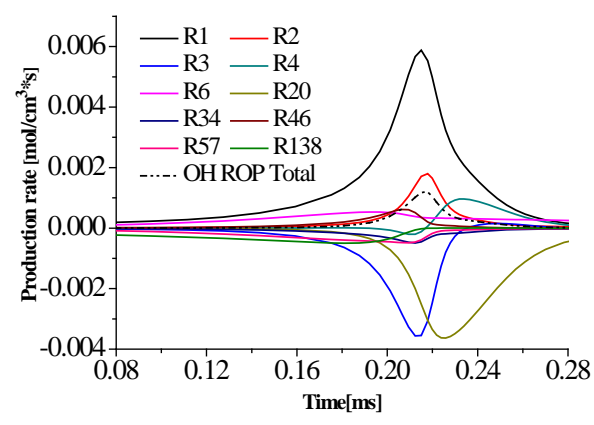

(a) $1400 \mathrm{~K}$

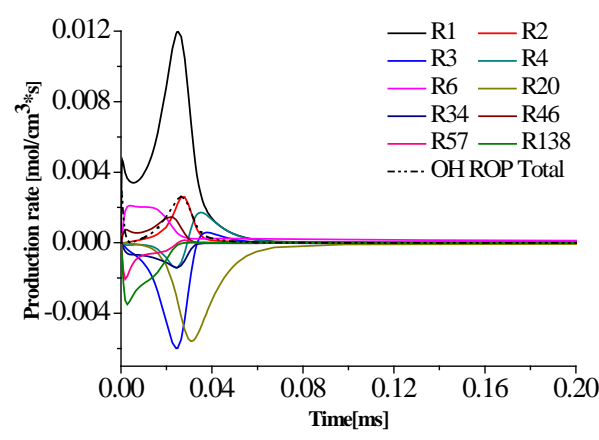

(b) $1700 \mathrm{~K}$

Fig.5 $\mathrm{OH}$ radical reaction path analysis under different temperatures $(\mathrm{P}=1 \mathrm{~atm}, \phi=1.0$ ) 


\section{Conclusion}

Surrogate fuel model (n-decane+trimethylbenzene) mechanism was used to numerical study the $\mathrm{OH}^{*}$ radicals reaction process of RP-3 kerosene's auto-ignition in shock tube, and dominant production and consumption reactions were find out. Double peaks curve of $\mathrm{OH}^{*}$ emission was found to be caused by different leading production and consumption reaction paths after comparing reaction paths under different temperatures. Different time scale of production peak and consumption peak lead double peaks under lower temperature. While more consumption reaction paths caused higher global consumption under higher temperature and thus one peak curve of $\mathrm{OH}^{*}$ emission.

\section{References}

[1] Subith S.Vasu, David F.Davidson, Ronald K.Hanson. Shock-Tube Experiments and Kinetic Modeling of Toluene Ignition[J]. Journal of Propulsion and Power, 2010, Vol.26, No.4:776-783.

[2] D.F.Davidson, B.M.Gauthier, R.K.Hanson. Shock tube ignition measurements of iso-octane/air and toluene/air at high pressures[C]. Proceedings of the Combustion Institute, 30(2005):1175-1182.

[3] D.C.Horning, D.F.Davidson, R.K.Hanson. Study of the High-Temperature Autoignition of n-Alkane $/ \mathrm{O}_{2} / \mathrm{Ar}$ Mixtures[J]. Journal of Propulsion and Power, 2002, Vol.18, No.2:363-371.

[4] M.A.Oehlschlaeger, D.F.Davidson, J.T.Herbon, et al. Shock tube measurements of branched alkane ignition times and $\mathrm{OH}$ concentration time histories[C]. 41 ${ }^{\text {st }}$ Aerospace Sciences Meeting and Exhibit, 6-9 January 2003, Reno, Nevada.

[5] Daniau E, BouchezM, Bounaceur R, et al. Contribution to scramjet active cooling analysis using n-dodecan decompostion model as a generic endothermic fuel[C]. $12^{\text {th }}$ AIAA International Space Planes and Hypersonic Systems and Technologies, Norfolk, U.S. 2003.

[6] Dagaut P, Cathonnet $M$. The ignition, oxidation, and combustion of kerosene: A review of experimental and kinetic modeling[J]. Progress in Energy and Combustion Science, 2006, 32:48-92.

[7] Violi A, Yan S, Eddings E G, et al . Experimental formulation and kinetic model for JP-8 surrogate mixture[J]. Combustion Science and Technology, 2002 , 174(11-12):399-417.

[8] Honnet S, Seshadri K, Niemann U, et al. A surrogate fuel for kerosene[J]. Proceedings of the Combustion Institute, 2009, 32(1):485-492.

[9] CHEN Qisheng, DOU Zhiguo, LI Lan, et al. Experimental study on ignition delay of kerosene and surrogate fuel[J]. Journal of propulsion technology (Accepted). 